$$
\text { August 29, } 1947
$$

\title{
EFFECT OF SUPPORT ON THE PERFORMANCE OF VANE ANEMONETERS
}

\section{INTRODUCTION}

In June 1947 it was decided to use the wind tunnel rather than the whirling arr for calibrating vane anemometers at the National Bureau of Standards. While the scatter of observations in a wind tunnel was usually greater than that obtained with the whirling arm, the absolute accuracy on the whole was known to be greater because the uncortainty associatea with swirl about a whirling arm was avoided.

In making the change to the wind tunnel, the question of the proper means of supporting an enomometer was brought to the fore. Since vane anenoneters were supplicd without support members of any sort, it was customary to pasten the onemoneter on a flat plate at the end of the whirling arm as shown in figure 1. It wes known that the support had some effect on the rate of the instrument, and to avoid possible error the instrument should be supported in the same way in use.

However, a flat plate was hardly a logical type of mounting for a user to choose, It was suspected too that an observer night at times hold the anorometer in his hand. To throw some light on the importance of this question, it was decided to investigate the performance of several sizes of vane anemometers of the type shown in rigures 1 to 5 on the various types of support shown in the figures. The investigation was conducted in the Bureau's $4 \frac{1}{2}$-foot wind tunnel.

\section{INTERFERENCE - FREE MOUNTING}

If an anemometer is suspended in a wind stream on wires so fine that they are incapable of producing interecence, the performance free from support interference may be obtained. By comparing the performance obtained in this way with that obtained on the rod-type of support shown in figure 2, it has been found that a rod no greater than $1 / 2$ inch in dicrieter produces no measurable interference when it extends airectly downstream. Effects from nembers supporting the rod itself may be reduced to negligible proportions by placing them at a sufficient distance domstrean. This requires a minum distance of the 
order of 16 times the diameter or cross-stream width of such members. In the mounting shown in figure 2 ample margin has been allowed, and the mounting is interference free. The portion of the rod directly under the anemometer is flattened to about $1 / 8$ inch in thickness. In the investigation of the interference produced by other types of support, the performance on the support in question was compared with that on the rod.

\section{OTHER SUPPORTS INVESTIGATWD}

\section{(a) Whirling-Arm Mounting}

The flat plate on which anemometers were mounted in the past for a whirling-arm test is shown in figuro 1. A wooden member simulating the end of the arn is shown to the right. The plate is $1 / 8$ inch thick and 3 inches wide. The distance from the end of the arm to the end of the plate is $121 / 2$ inches. The wind moves normal to the face opposite the dial and parallel to the flat side of the plate.

(b) Hand Support

The types of hand support shown in figures 3, 4, and 5 were chosen not as recommended methods of support, but rather as manners in which an observer might be inclined to hold an anemometer in making a measuroment of air speea. The models are intended to represent aproximately an adult hand and arm. The arm length is not intended to be correct, and the body is not represented. This would correspond to the case where the observer's body is completoly outside the wind stream. Figures 1 to 5 all show a 4 -inch anemometer, the size referring to the inside diameter of the cylinarical housing.

Figure 3, hand No. 1 shows one finger through the ring of the anemometer and two fingers supporting the housing. The arm extends to the side and is at right angles to the wind.

Figure 4, hand No. 2 shows one finger through the ring allowing the anemoneter to hane down frocly. The arm is at right angles to the wind.

Figure 5, hand No. 3 shows an anemometer being held by means of a short handle. The arm is directly downwind inclinod at an angle of 45 degrees to the wind. 


\section{RESULTS}

Curves "showing the performance of a 3-inch, a 4-inch, and a 6-inch anemometer are given in figures 6,7 , and 8 respectively.

The speed indicated by an anemometer depends on the rate of rotation of the vane wheel, which in turn depends on the setting of the vanes, the diameter of the wheel, the speed of the air through the wheel, and the friction of the instrument. The true speed is the speed of a uniform parallel flow of air that would exist if the anemometer and its supports were absent. The indicated speed may be less than, equal to, or greater than the true speed depending of the factors that control the rate of rotation of the vane wheel.

The performance given in figures 6,7 , and 8 is in terms of the ratio of the indicated speed to the true speed plotted against the true speed. Displacement of the various curves from that marked "rod" shows the altered porformance due to the interference of the support. It will be noted that the ratio of indicated to true speed is increased in every case. The reason for this is that the air speed through the instrument incresses locally due to the fact that the air must flow around tho support.

The changes in indicated speed due to interference are given in Table 1 as percentages of the true specd at several values of the true speed. There is an indication that the percentages decrease slightly with increasing speed, but the change is scarcely outside the experimental error. The column of avereges may therefore be used as a reliable index of the various interference effects. It will be seen that the interference effects are about the sare on the 3-inch and 4 -inch anemometers, but somewhat less on the 6-inch anemometer. A decrease with increasing size is to be expected because the anemoneter becomes larger relative to its support. Since hands No. 1 and No. 2 produced roughly the same effect, No. I was used only with the 4 -inch anemometer.

AIl of the effects demonstrated here are large compared to the inherent accuracy of a calibration curve. The scatter of the points about any one mean curve in figures 6,7 , and 8 shows that a calibration curve is defined to an accuracy of better than one percent. However, there may be systematic errors in the measurement of speeds below 400 feet per minute amounting to several percent, so that the scatter of observations is not a reliable indication of the absolute accuracy at the lower speeds. Nevertheless interference effects are likely to be the major source of error unless the 


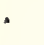


same support system is used at all times. The support therefore becomes in effect part of the instrument and changing it amounts to changing the instrument.

Not all interference effects will be as large as those shown here, for the effect depends entirely on the size, position and shape of the support. If the bulk of the support is to the rear of the anenoneter the oifect may bo in the opposite direction. It is entirely possible that some disposition of the support may be made such that effects from the side and effects from the rear just cancel. However, proper belance might be difficult to obtain over the entire speed range of an instrument and also would be affected by wind direction. Directional effects on anemometers without support interrerence are treated in reference 1.

\section{THE ADOPTION OF A STANDARD JNOUNTING FOR CAIIBRATION PURPOSES}

In considering the question of a standard mounting it is helpful to keep in mind the fact that any mounting must be regarded as part of the instrument. Since an anemometer supplied by a manufacturer should bo regarded as a complete instrument, it is assumea that nothing should be added to it. Therefore since the rod support is equivalont aerodynemically to adding nothing, the rod support of figure 2 has been adopted for the purpose of calibration.

Experience with vane anemometers at the National Bureau of standards has shown that it is possible to employ the rod support under nearly all conditions of use. Even when it is necessary to use a short rod the intorference from the member holding the rod is likely to be small. According to reference I, for example, the clamping device and strut shown in figure 9 had a nogilgible effect at distances downstream of one foot or nore. Evon at 4 inches the intererence effect was only of the order of one or two nercent. Tho strut in this case wes $11 / 4$ inch thick and 3 inches wide and extended completely across the tunnel.

\section{REFERENCE}

1. Heald, Roy H. and Ballif, Paul S.: Effect of Yaw on Vane Anemometers. National Bureau of Standards Journal of Rescarch, Vol. 19, Resacrch Paper RP 1056, Dec. 1937. 


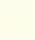


same support system is used at all times. The support therefore becomes in effect part of the instrument and changing it amounts to changing the instrument.

Not all interference effects will be as large as those shown here, for the effect depends entirely on the size, position and shape of the support. If the bulk of the support is to the rear of the anemoncter tho eifect mey be in the opposite direction. It is entirely possible thet some disposition of the support may be made such that effects from the side and effects from the rear just cancel. However, proper balance might be difficult to obtain over the entire speed range of an instrument and also would be affected by wind direction. Directional effects on anemometers without support interference are treated in reforonce 1 .

\section{THE ADOPTION OF A STANDARD MOUNTING FOR CAIIBRATION PUREOSEŚ}

In considering the question of a standard mounting it is helpful to keep in mind the fact that any mounting must be regarded as part of the instmument. Since an anemometer supplied by a manufacturer should bo regarded as a complete instrument, it is assumea that nothing should be added to it. Therefore since the rod support is cquivalont aerodynemically to ading nothing, the rod support of figure 2 has been adopted for the purpose of calibration.

Experience with vane anemometers at the Nationel Bureau of Stendards has shown that it is possible to employ the rod support under nearly ail conditions of use. Even when it is necessary to use a short rod the intorference from the member holding the rod is likely to bo small. According to reference I, for example, tho clemping devico and strut shown in figure 9 had a negligible effoct at distances downstream of one foot or more. Even at 4 inches the interferenco effect was only of the order of one or two nercent. The strut in this case was $11 / 4$ inch thick and 3 inches wide and extended completely across the tunnel.

\section{RETERTIVE}

1. Heald, Roy H. and Ballif, Paul S.: Effect of Yaw on Vane Anemometers. National Bureau of Standards Journal of Research, VoI. 19, Restarch Paper RP 1056, Dec. 1937. 


\begin{abstract}
TABIE 1
Change in Indicated Speed Due to Interference, Txpressed as Fercentige of True Speed.
\end{abstract}

Support

$400 \quad 600 \quad 800 \quad 1200 \quad 1600$

Rod

Flate

Hand No. I

Fand No: 2

0

3-Inch Anemometer

Hand No. 3

5.6

5.6

$15.6 \quad 16 . \overline{1}$

$5 \cdot 4$

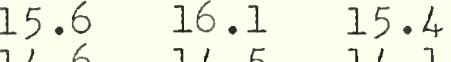

5.0

14.514 .1

14.4

13.4

4-Inch Aneriometer

Rod

$\begin{array}{lr}\text { Plate } & 5.5 \\ \text { Hand No. I } & 18.1\end{array}$

0

5.3
17.1

0
5.4

Hand No. 2

$18.1 \quad 16.9$

Hand No. 3

11.5

11.811 .9

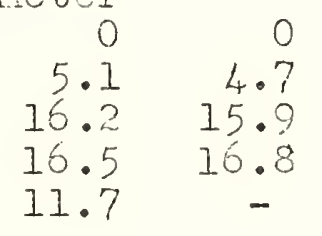

0
5.2
16.8
17.0
11.7

Rod

Plate

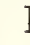
Han Hend No. Hand No.

6-Inch Anononeter
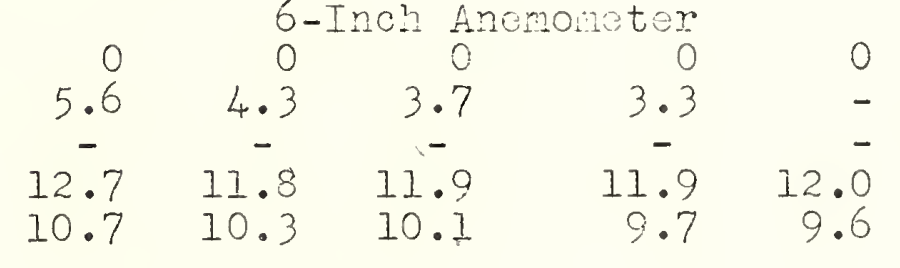

0
4.2
-
12.1
10.1




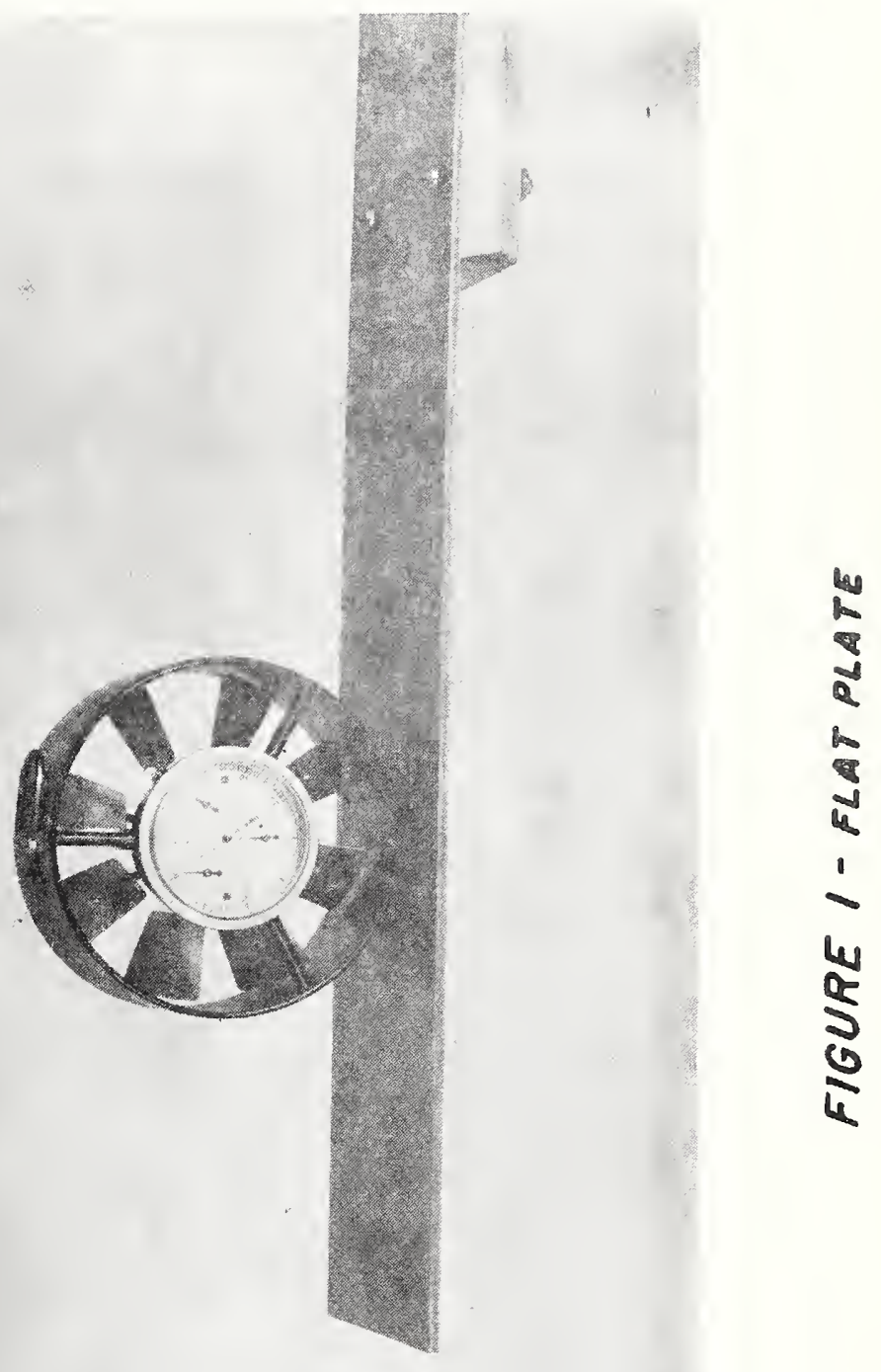




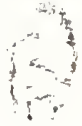




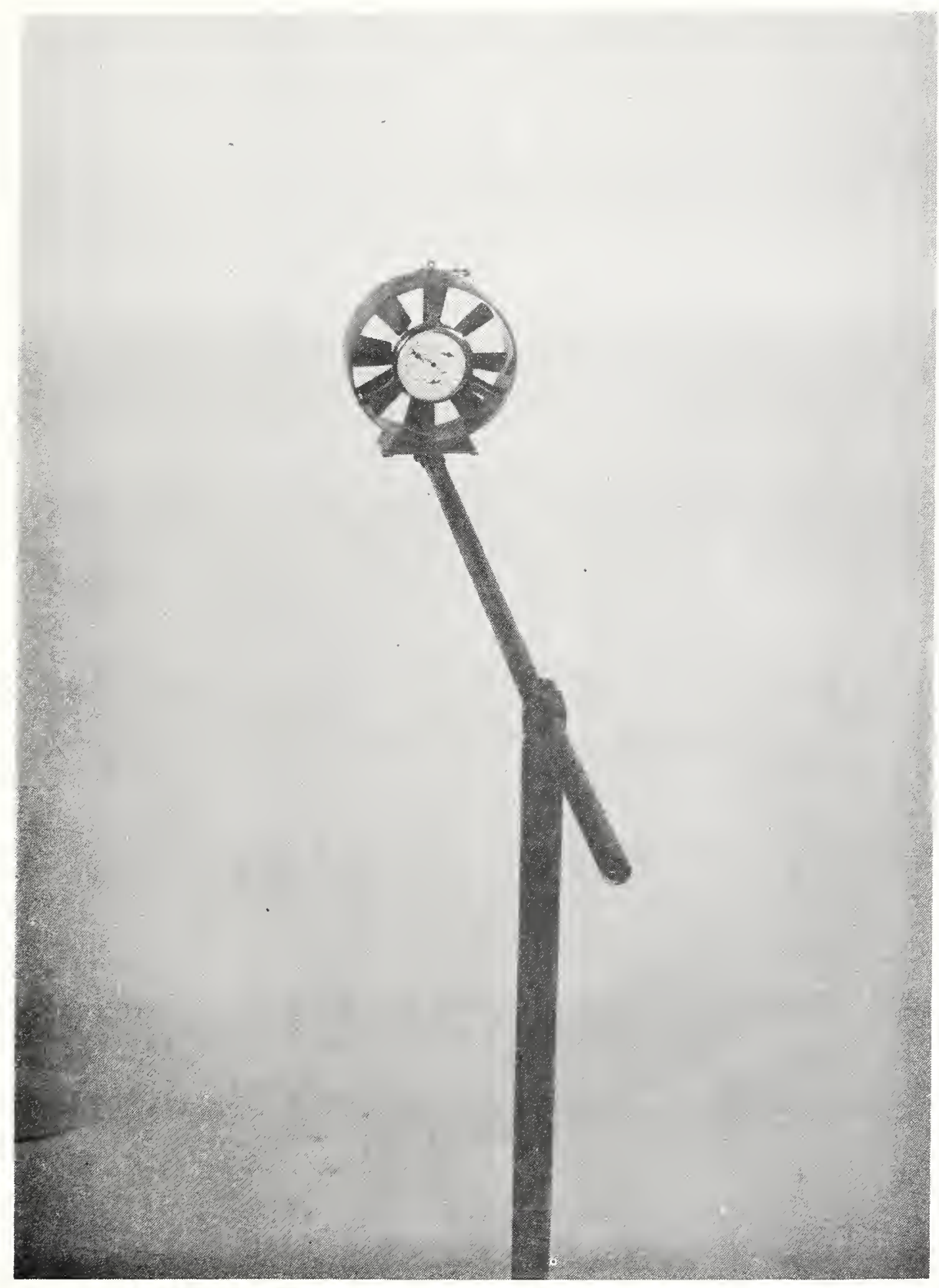

FIGURE 2 - ROD SUPPORT 


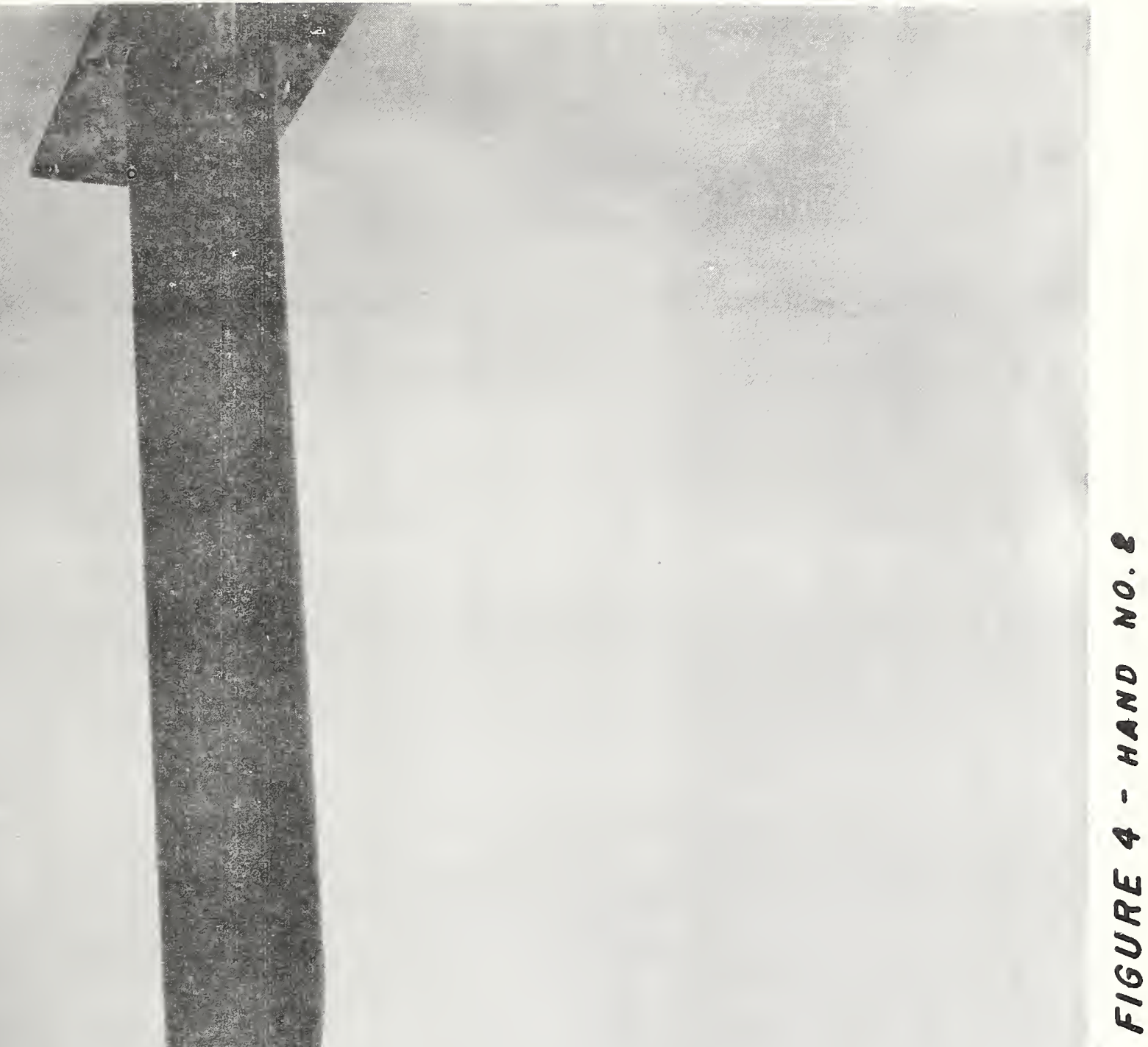




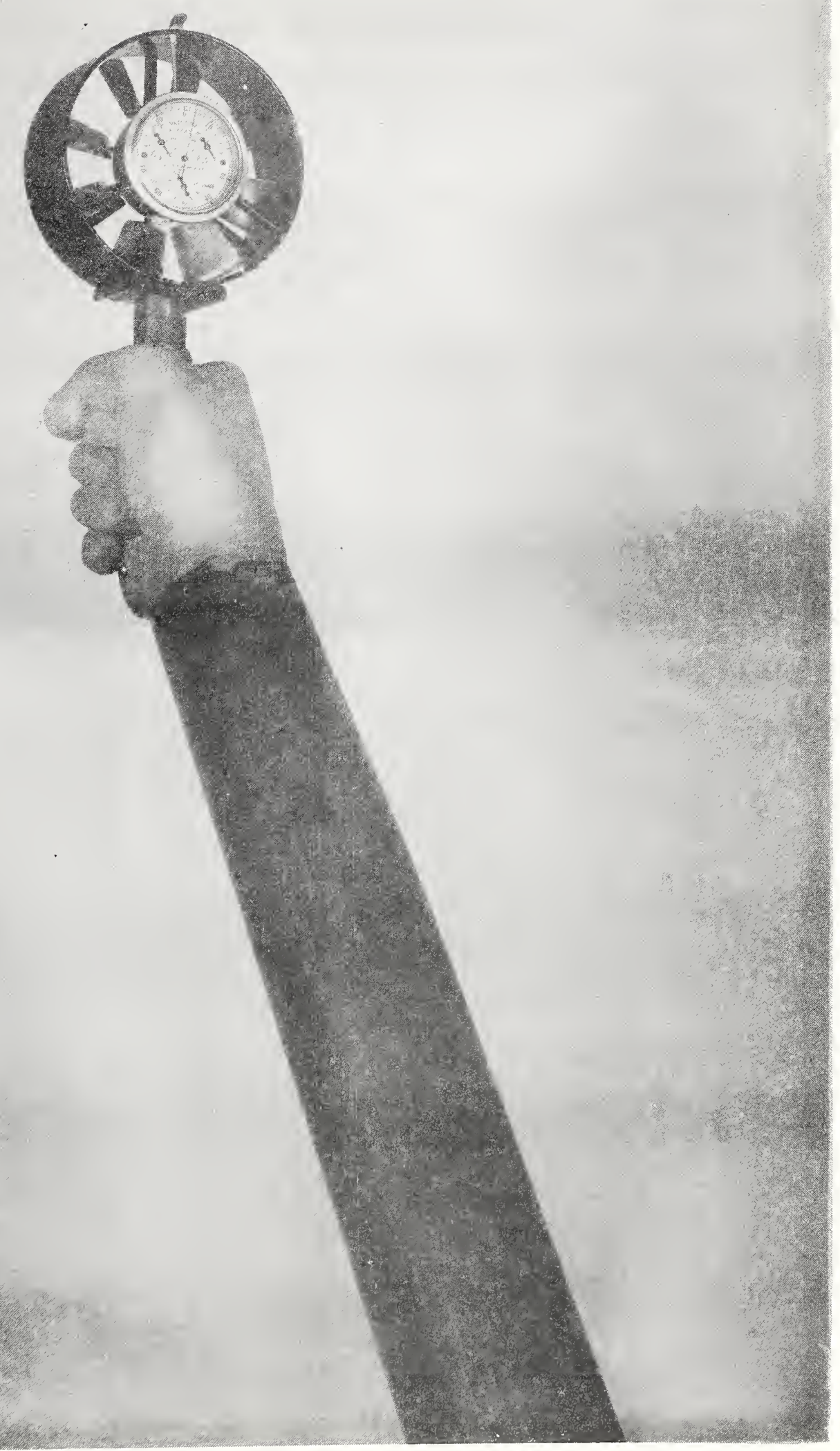

FIGURE 5 - HANO NO.3 
, 


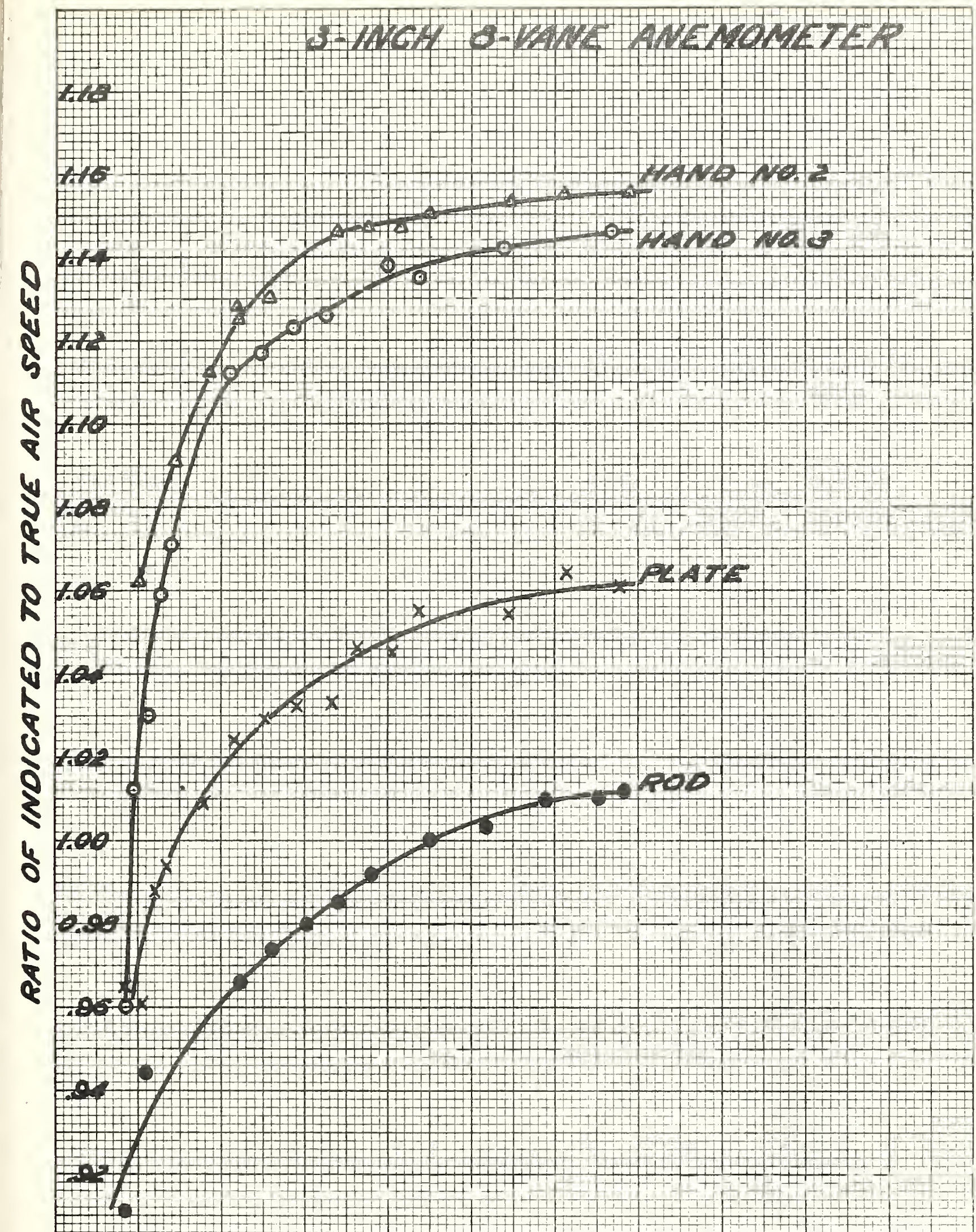

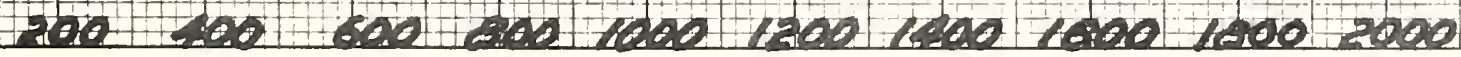
TRUE AIP SPEEO - FEET PEP MINUTE FIGUPE G 


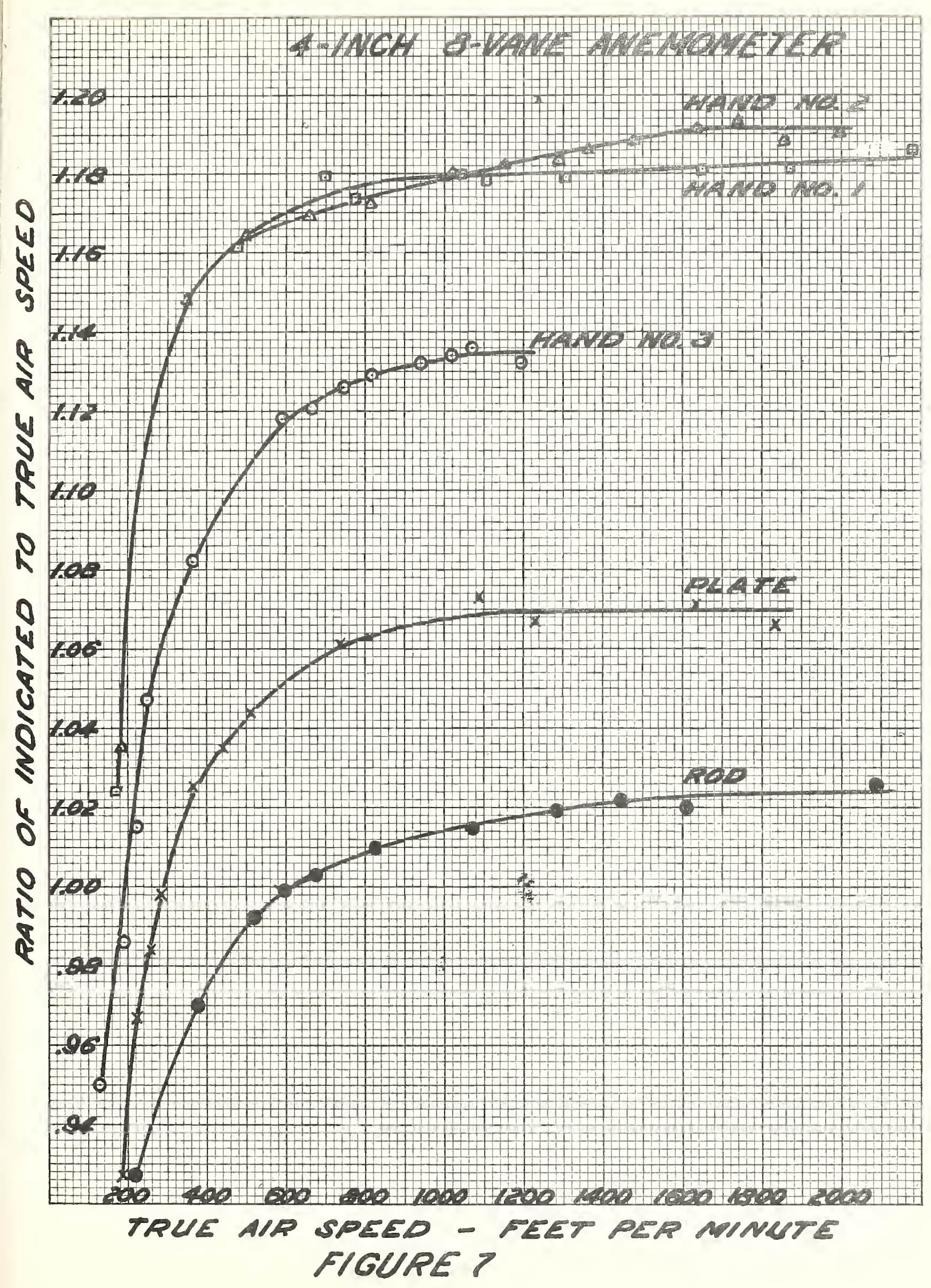


. 


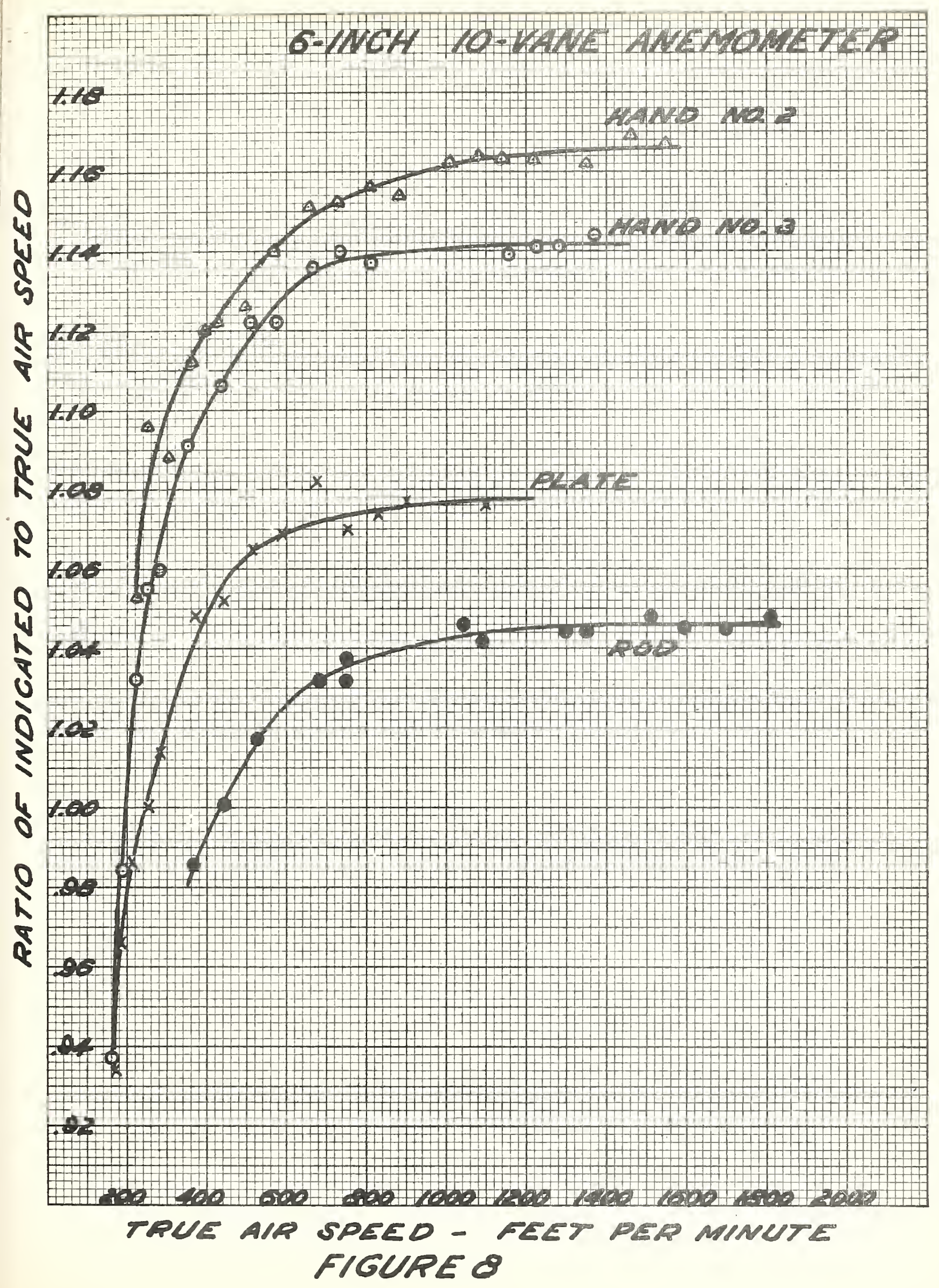



